\title{
La sociedad de lo descartable y otras vicisitudes del mundo postmoderno
}

\author{
The society of the disposable and other vicissitudes of the postmodern world
}

Manuel Arboccó de los Heros $^{1}$

\begin{abstract}
RESUMEN
La sociedad postmoderna hace mención a una particular época con cambios y características en los aspectos sociales, morales, económicos y culturales, propios de los últimos treinta o cuarenta años, aproximadamente. En términos generales, es una sociedad de mucha producción y gran consumo, donde reina y domina la tecnología, donde aparecen y desaparecen figuras mediáticas (pequeños ídolos), con un relativismo galopante, una pluralidad de opciones de todo tipo, una revisión y cuestionamiento (si no caída) de los grandes dogmas, una cultura de la imagen junto a una defensa del individualismo y una "psicología del éxito" a veces mal entendida así como una búsqueda casi obsesiva por una felicidad que contradice con los altos niveles de ansiedad, estrés y vacíos existenciales. En fin, una sociedad compleja como siempre han sido las sociedades humanas pero que ha roto en definitiva con mucho de lo clásico y tradicional. Con sus posibilidades y con sus tragedias, como muchas. Presentamos este pequeño ensayo sobre la cultura de estos tiempos, esperando, como siempre, contribuir al debate académico
\end{abstract}

\section{Palabras clave}

Postmodernidad, individualismo, existencialismo, consumismo, vacío existencial, la cultura del selfie, incomunicación, relaciones humanas.

\begin{abstract}
In the past thirty or forty years, approximately postmodern society points out a particular time fraught with changes and distinctive characteristics in social, moral, economic and cultural aspects. In general terms, it is a society with a high level of production and mass consumption, where technology is pervading, and media figures pop up and disappear (small idols); a society with a rampant relativism, a plurality of options of all kinds, a calling into into question (if not fall) of great dogmas, a culture of the image along with a defense of individualism and sometimes a misunderstood "Psychology of success", as well as an almost obsessive quest for happiness that is in contrast to high levels of anxiety, stress and existential vacuum. In sum, a complex society as always have been human societies but that has broken in a short time a lot of the classic and traditional. With their possibilities and with their tragedies, like many others. We present this small essay on the culture of these times, in the hope, as always, of contributing to the academic debate
\end{abstract}

\section{Keywords}

Postmodernity, individualism, existentialism, consumerism, existential vacuum, the selfie culture, lack of communication, human relations.

\section{A manera de introducción: ¿Qué es el postmodernismo?}

Hoy, vivimos la sociedad postmoderna, un proceso cultural manifiesto en muchos países en las últimas cuatro décadas, aproximadamente. Grandes autores como Lyotard (la condición posmoderna), Baudrillard (la sociedad de consumo), Lipovetsky (la era del vacío), Bauman (modernidad líquida),

Psicólogo y psicoterapeuta. Magister en Psicología por la UNMSM. Docente de la Universidad Femenina del Sagrado Corazón y de la Universidad Inca Garcilaso de la Vega. Magister en Psicología. Articulista del Diario El Peruano. 
Vattimo (pensamiento débil), entre otros, llaman postmodernismo a una época que se manifiesta, entre otras formas, por una inmensa producción y por ende un aumento desmedido del consumo; así, los medios y la industria del consumo masivo se convierten en centros de poder. Hay también una excesiva emisión de información (frecuentemente contradictoria), a través de todos los medios de comunicación; se debilita la ideología como forma de elección de los líderes, siendo reemplazada por la imagen, vivimos por eso la cultura de la imagen, como propone Sartori (2004). Los medios masivos se convierten en transmisores de la verdad, lo que se expresa es el hecho de que lo no mostrado por un medio de comunicación masiva simplemente no existe para la sociedad. Sartori (ob. cit) nos dice que la gente cree en lo que ve en televisión, lo que a su vez lleva a que desaparezcan las grandes figuras carismáticas y referenciales y vayan surgiendo una infinidad de pequeños ídolos que duran hasta que surge algo más novedoso y atractivo.

En estas sociedades, observamos con preocupación que frente al compromiso riguroso con la verdad y la rigurosidad, el posmodernismo defiende la hibridación, la cultura popular, el descentramiento de la autoridad intelectual y científica y la desconfianza ante los grandes relatos históricos.
Además, la verdad es cuestión de perspectiva o contexto más que algo universal.

Seguidamente, se pierde la intimidad, y la vida de los demás se convierte en un show, especialmente en el contexto de las redes sociales. Existe también una banalización de la política (hoy cualquiera se lanza a la esfera pública) y una desmitificación de los líderes; los individuos solo quieren vivir el presente; el futuro y el pasado pierden importancia. Hay una búsqueda de lo inmediato (visión de corto plazo) y se rinde culto al cuerpo y la liberación personal. Declive del imperio de la razón por un hedonismo corporal y una hipervaloración del cuerpo.

Consideramos una dudosa propuesta de la psicología del "éxito". Mal entendido el éxito se queda a un nivel de superación económica. En contraposición con la modernidad, la posmodernidad es la época del desencanto. Se renuncia a las utopías y a la idea de progreso de conjunto. Se apuesta a la carrera por el progreso individual, además de ser una cultura hipertecnológica y de la velocidad, con niveles de estrés peligrosos.

Luego de estas características, veamos más detenidamente algunas situaciones que estamos viviendo en estos tiempos:

\section{Postmodernidad, vínculos y vacíos ${ }^{2}$}

Esta sociedad facilita el sexo, pero no así el amor ${ }^{3}$

La liquidez de las relaciones y los vínculos flojos son alentados por muchas sociedades hoy ${ }^{3}$. La sociedad actual no solo roba el tiempo libre sino, además, llena de bulla la vida. Hoy está de moda el conductor de radio que grita, que habla rápido, que pone canciones una tras otra sin descanso, o esa publicidad que aparece y cual metralla dispara palabras sin pausa alguna. También la TV con sus cientos de horas de contenidos insustanciales y superficiales, pero con un rating asombroso. El filósofo Kierkegaard decía que el hombre que no tiene la conciencia tranquila no puede aguantar el silencio. Esta sociedad le teme al silencio, a la pausa, al diálogo calmado y a la sobremesa. Nos parece que muchas parejas hoy ocultan la

\footnotetext{
2 Ponencia realizada por Manuel Arboccó en el VIII Congreso Latinoamericano de Psicoterapia Existencial y en el I Congreso Nacional de Psicoterapia Existencial realizado en Lima del 15 al 17 de setiembre del 2016.

3 Sobre este punto, el lector puede remitirse a Arboccó (2015) donde hay un trabajo más extenso. Aquí solo se resume.
} 
gran distancia que los separa con el volumen de la radio o del equipo musical.

Esta sociedad hace de la privacidad un espectáculo y no tolera las muestras de sentimiento genuino, prefiere la frialdad televisada y el consumismo del mercado. Vemos en la TV -llamada basura desde hace un tiempo- (Arboccó y O'Brien, 2012) cómo en muchos realitys se crean relaciones de pareja que tras uno que otro escándalo terminará como efímera muestra del valor de una relación de pareja. Y miles de jóvenes observan esos programas y admiran y se identifican con esos "modelos"4.

El filósofo español Fernando Savater en su libro Las preguntas de la vida señala que "las sociedades modernas de masas tienden a despersonalizar las relaciones humanas, haciéndolas apresuradas y burocráticas, es decir, muy "frías" si se las compara con la "calidez" inmediata de las antiguas comunidades, menos reguladas, menos populosas y más homogéneas" (Savater, 2007, p. 195).

"El mundo actual es un mundo Popeye" nos dice el psicólogo y logoterapeuta Claudio García Pintos en su texto La vida es una moneda. Así "la fuerza viene en forma de lata de cerveza, pastillas para dormir, para tener mayor vigor sexual, teléfonos de ultimísima generación y automóviles espectaculares que marcan mi nivel social, etc. Creemos ser lo que tenemos, lo que ostentamos, lo que hacemos. Compramos, consumimos, tomamos, pero la aguja sigue sin ser encontrada" (García, 2010. p. 90). Por tanto, el hombre actual (niño o adulto) consume nimiedades y ocurre algo curioso: se hace adicto a estas y ya no puede en adelante consumir menos de ellas, necesita igual o mayor cantidad para no padecer el respectivo síndrome de abstinencia y así, seguirá embotado.

LaprofesoratitulardeFilosofíadelaUniversidad de São Paulo, Olgária Matos, nos recuerda que en el siglo pasado, el filósofo Walter Benjamin ya hablaba sobre la pobreza de la experiencia en el mundo contemporáneo, que es el mundo de las cosas intrascendentes. Con el paso del tiempo, las personas tienen mayor dificultad de diferenciar lo significativo de lo intrascendente. Los selfies — señala Matos, por dar un ejemplo-son una materialización de la pobreza de experiencias, porque, en general, no hay ninguna historia detrás de esas imágenes que están imbuidas en un narcisismo obsoleto. Ellas revelan el vacío de la experiencia (Matos, 2014, p. 7). Esto se relaciona con lo que proponía Viktor Frankl, el creador de la logoterapia, quien nos recuerda que "el vacío existencial es un fenómeno muy extendido en el siglo XX" (Frankl, 2004, p. 113), seguidamente dice: "El vacío existencial se manifiesta principalmente en un estado de tedio (aburrimiento)" (ob. cit., p. 114). Vivimos tiempos donde no abundan los vínculos profundos y extendidos, se cree que el vínculo no debe obedecer nada más que a mi comodidad y al "respeto de mis derechos", "nada ni nadie puede obligarme" y finalmente "hago con mi cuerpo lo que quiero", que mal entendidos como son, hacen muy tenue la presencia del otro e imposibilita el encuentro Yo-Tú como diría el filósofo Martin Buber. Recordemos ese estribillo de una canción popular peruana muy solicitada hace unos años en radios locales: "soy soltera y hago lo que quiero". La liquidez de las relaciones y los vínculos son alentados por muchas sociedades hoy en día, lamentablemente.

"Este nuevo narciso —nos dice el psicólogo y terapeuta Ramiro Gómez- navegante de los mares de internet, no profundiza, no ahonda nada, se da por satisfecho con el resumen, casi con la definición más escueta. Tiene pereza de pensar, salvo si ese dramático esfuerzo se orienta a escalar posiciones de poder dentro del mercado, o de la posibilidad del poder por el poder" (Gómez, 2013. p. 107).

En su libro titulado Poliantea, Marco Aurelio Denegri señala "el amor depende del

\footnotetext{
4 Según la encuesta de CONCORTV (Consejo consultivo de radio y televisión nacional) el 52,8\% de niños y adolescentes entre 7 y 16 años, de los más de 9000 encuestados, aspira ser de adulto como un "chico reality". Disponible en: http:// elcomercio.pe/lima/52-8-ninos-aspira-chicos-reality-273293.
} 
desarrollo integral de la persona: pero si esta se ha desarrollado parvamente y con suma deficiencia, entonces su amor será, si acaso, como su imperfectísimo desarrollo" (Denegri, 2014, p. 52), quizá por eso el amor es hoy una tarea difícil para millones, quizá es solo una capacidad (o un arte según el psicoanalista Erich Fromm) que solo presentan muy pocos, como diría el maestro José Ortega y Gasset. Recordemos que la capacidad de amar, como cualquier otra capacidad, dependerá del nivel de desarrollo y realización personal. Por su parte, Fromm en su libro El arte de amar proponía lo siguiente:

Para la mayoría de la gente, el problema del amor consiste fundamentalmente en ser amado, $y$ no en amar, no en la propia capacidad de amar. De ahí que para ellos el problema sea cómo lograr que se los ame, cómo ser dignos de amor. Para alcanzar ese objetivo, siguen varios caminos. Uno de ellos, utilizado en especial por los hombres, es tener éxito, ser tan poderoso y rico como lo permita el margen social de la propia decisión. Otro, usado particularmente por las mujeres, consiste en ser atractivas, por medio del cuidado del cuerpo, la ropa, etc. (Fromm, 2007a, p.11).

Según Matos, "hay también un reemplazo muy rápido en el ámbito de las relaciones amorosas, $e$ incluso las relaciones profesionales están fragmentadas. Ya no se trata más de "el" empleo de toda la vida. Todo eso tiene que ver con la cultura del exceso, de la caducidad, que esclaviza a las personas" (Matos, 2014, párr. 11). El capitalismo contemporáneo está definido por la presencia de lo descartable y a corto plazo. "Vivimos un tipo de capitalismo que hace que las personas confundan el vacío como una carencia y la carencia como un objeto faltante, y eso nos conduce a la imposibilidad de convivir con el vacío y ser su artesano", concluye la filósofa Olgária Matos (Matos, 2014, párr. 11). Fromm, lo citamos nuevamente, nos dice: "Hoy nos encontramos con personas que obran $y$ sienten como si fueran autómatas; que no experimentan nunca nada que sea verdaderamente suyo; que se siente a sí mismas totalmente tal como creen que se las considera; cuya sonrisa artificial ha reemplazado a la verdadera risa; cuya charla insignificante ha sustituido el lenguaje comunicativo; cuya sorda desesperanza ha tomado el lugar del dolor auténtico" (Fromm, 1964, p. 21).

El recientemente fallecido Zygmunt Bauman, sociólogo y filósofo polaco de origen judío (quien acuñara el concepto de modernidad líquida para referirse a sociedades globales, capitalistas, hipertecnológicas, y de muchos cambios sociales desde los años 60 aproximadamente) en su libro Vida de consumo propone que las personas nos hemos vuelto una masa de consumidores engañados, seducidos, arrastrados y manipulados todo el tiempo por la publicidad (Bauman, 2007). Inclusive nuestros vínculos están variando violentamente, al respecto Bauman menciona: "los clientes habituales de las agencias de citas por internet, engolosinados por las prácticas del mercado, no se sienten nada cómodos en compañía de seres humanos de carne y hueso. El tipo de productos con los que fueron entrenados para socializar son para el tacto, pero no tienen manos para tocar" (ob. cit. p. 31).

En este mundo cibernético y ya de robots, de pronto las relaciones humanas cálidas están debilitándose, estando como estamos todo el día conectados a máquinas y aplicaciones, vamos perdiendo ese sabor humano que es parte importante del sentido de la vida. "El encuentro con una persona viva requiere de habilidades sociales de las que uno puede carecer o que pueden resultar inadecuadas, $y$ entablar un diálogo siempre implica exponerse a lo desconocido" (ob. cit. p. 32).

En su estimulante libro, El dilema del hombre, el psicólogo Rollo May señala:

En una época como ésta, cuando la sociedad ya no proporciona al individuo la orientación psicológica $y$ ética adecuada, éste se ve 
obligado, a veces por desesperación, a examinarse profundamente para descubrir una nueva base a fin de orientarse e integrarse. Esta necesidad dio origen al psicoanálisis y a la nueva psicología dinámica; de hecho, el apoyo al individuo para que descubra una nueva unidad dentro de sí mismo es la gran contribución de la psicología desde Freud en adelante. La satisfacción de esta necesidad del hombre moderno de encontrar su significado dentro de sí mismo es también lo que motivó la aparición del existencialismo (May, 2000, p. 79).

\section{Gergen y la presencia ausente}

La presencia ausente, en palabras del psicólogo y profesor estadounidense Kenneth Gergen (2002), constituye la presencia mental y social de una persona en varios lugares a la vez, que se hace evidente con la utilización de la tecnología actual, por ejemplo, de los teléfonos móviles, por no hablar del skype. Un individuo puede estar físicamente presente en un lugar pero mental $y$ socialmente ausente al estar conectado y concentrado con su celular, digamos. También puede estar físicamente ausente en un lugar pero mental y socialmente presente gracias al mismo dispositivo digital. Hablamos de los espacios reales y de los espacios "móviles" (La Rosa, 2012, p.73).
Hace un tiempo, en la Universidad, un estudiante refirió que estando en una reunión social se percató que si bien él y sus amigos estaban juntos, en un momento "no estaban juntos" pues cada uno de los asistentes había cogido entre sus manos su teléfono móvil y se dedicaba a él dejando a un lado el contacto real, motivo de la reunión. Curiosamente, no se encontraban precisamente reuniéndose y "en contacto" (Ver imagen $\mathrm{n} .{ }^{\circ} 1$ ). Reconocemos que también lo hemos visto, y no deja de sorprendernos y generarnos cuestionamientos e hipótesis. Hasta hay ahora un nombre para eso, en inglés, lo llaman phubbing (Ver imagen $\mathrm{n} .^{\circ} 2$ ) o la terrible costumbre de ignorar al que está al lado para conectarse al celular, sea en una reunión laboral o en el desayuno dominical familiar. O como en los conciertos cuando las personas escriben que están asistiendo al concierto en vez de vivirlo y entregarse al momento, al aquí y al ahora como nos recuerdan los psicoterapeutas humanistas y existencialistas. Hasta se toman una foto a sí mismos, lo llaman selfie, y lo suben para dejar registrado que están en el espectáculo. Probablemente, es una nueva forma de comunicación que tal vez tenga sus pro y no solo sus contra. No lo sabemos. Seguramente también estas son prácticas mayoritariamente de los llamados nativos digitales, es decir, las personas jóvenes nacidas no hace más de dos décadas cuando la era digital y tecnológica se empezaba a despuntar. Como inmigrantes digitales que somos, no compartimos esto, no siempre lo entendemos ni nos gusta, inclusive hemos llegado a sentirlo deshumanizante. Pero es un fenómeno creciente y dudamos mucho que desaparezca, como pasa a veces con otras modas pasajeras.

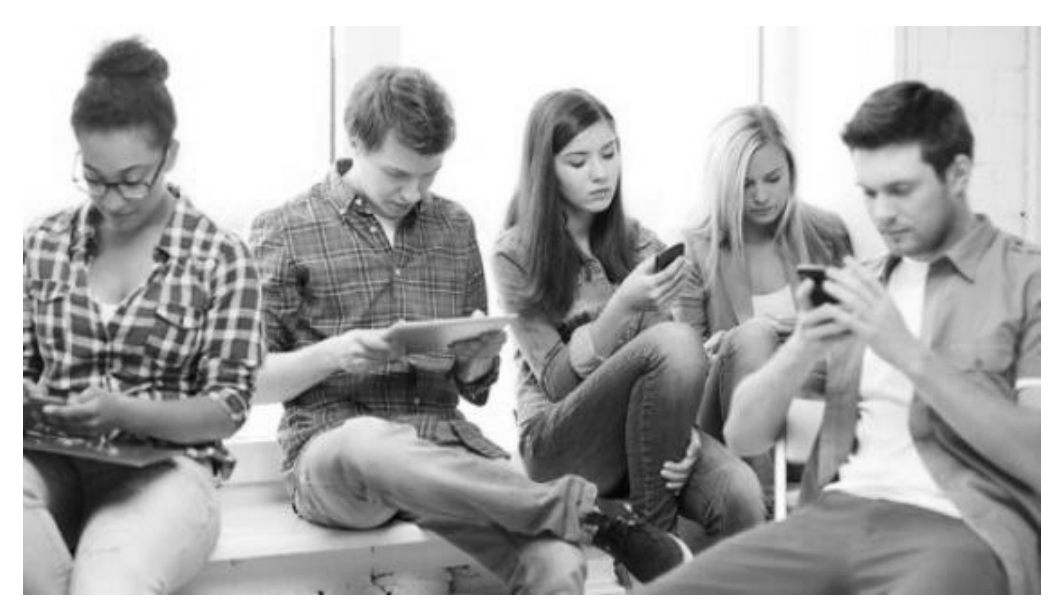

Imagen 1. Típica escena observada en los hogares, en las reuniones, en la escuela y en el trabajo. Acompañados pero desconectados, pegados a un aparato. Recuperado de: http://media.graytvinc.com/images/564*315/ phubbing-title-500x330.jpg 


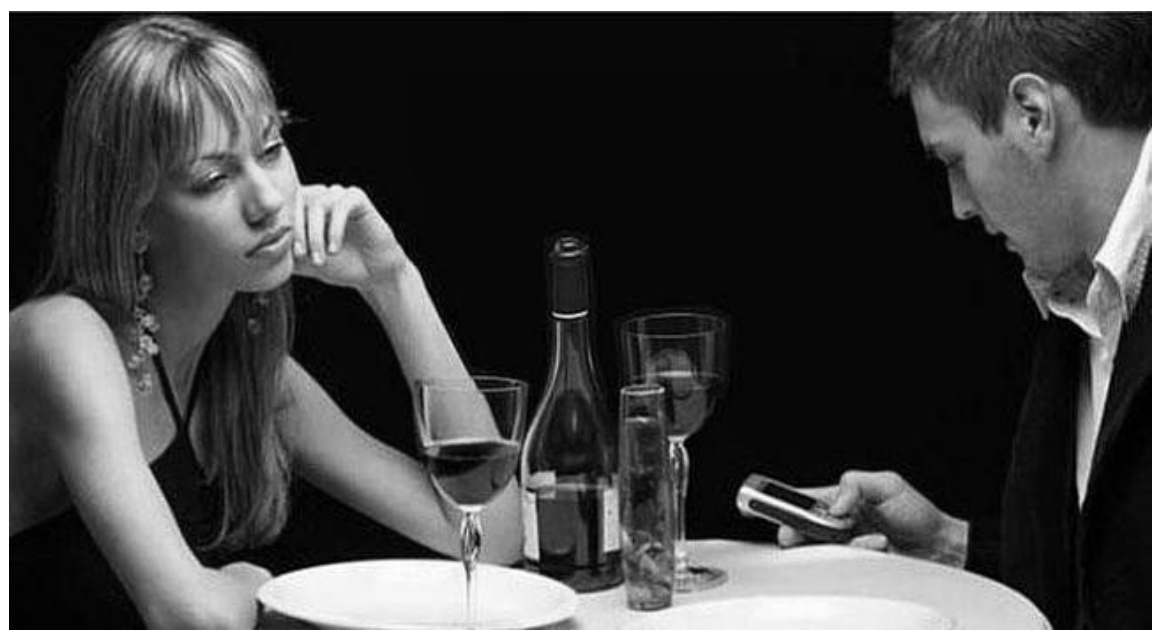

Imagen 2. ¿Es imposible "desconectarse" de las redes para conectarse con las personas? ¿o es que se prefiere el contacto no humano? A lo mejor, el llamado phubbing cumple un rol. Recuperado de: http://www.ideal.es/granada/noticias/201312/07/Media/otra/phub--647x350.jpg

\section{De selfies, autómatas y zombis}

Según el diccionario oficial, un zombi es aquella persona "que se supone muerta y que ha sido reanimada por arte de brujería, con el fin de dominar su voluntad"; y en su segunda acepción, considera un "zombi" como alguien "atontado, que se comporta como un autómata" (RAE, 2017).

Nos preguntábamos porque parece existir tanta fascinación últimamente por las películas, video juegos y series de zombis, estos seres generalmente descritos como muertos que regresan a un estado particular de vida donde deambulan sedientos de sangre y empujados por tendencias biológicas instintivas (más que por decisiones cerebrales corticales) a alimentarse de carne humana, por ende, a matar. Y nos parece que una posible respuesta está en lo que viene ocurriendo en algunos lugares y con algunas personas en esta era digital y tecnocrática. Si observamos, vamos a ver muchos "zombis tecnológicos", esto es, personas que presa (sí, ya son presas) de su lap top, de su moderno celular o de cualquier otro artefacto, se abstraen de todo (personas, lugares, eventos, reuniones) y casi en un estado hipnótico solo pueden ver lo que viene pasando en su equipo. De pronto, hoy más que antes, andamos como zombis, habiendo entregado el autocontrol a nuestros equipos y sus aplicaciones. Quizá hasta nos sentimos identificados con esos personajes de moda, o nos vemos retratados en ellos.

Según antiguas y fantásticas leyendas, si uno de estos zombis nos muerde, nos convertimos a su vez en uno de ellos. De alguna forma, en esta sociedad, pasa algo así con las modas y los usos compartidos. Desde que tenemos uno de esos aparatos o desde que entramos a formar parte de estas "redes" virtuales, somos parte también del colectivo, claro está que algunos pierden más rápido el manejo que otros. Hablamos de artefactos y programas que son capaces de anular la voluntad de quienes los usan, algo parecido al efecto de ciertas sustancias psicoactivas, inclusive ya hablamos desde hace unos años de adicciones digitales o tecnoadictos.

Se relata también casos tristes de accidentes (algunos mortales) por priorizar los selfies (autorretratos, generalmente tomados con la cámara de un celular y compartidos en las redes), no olvidemos los belfies (fotografiar el propio trasero), drelfies (fotografiarse en estado de embriaguez, léase borracho o borracha). Es curioso que la palabra "selfie" fue elegida como palabra del año 2013 por los diccionarios Oxford de lengua inglesa, tras extenderse significativamente su uso. 


\section{Los tiempos del hiperconsumismo}

Quien no está preso de la necesidad, está preso del miedo: unos no duermen por la ansiedad de tener las cosas que no tienen, y otros no duermen por el pánico de perder las cosas que tienen

Eduardo Galeano

Existen investigaciones periódicas que señalan a ciertos países (Canadá, Austria, Finlandia, Suiza) con los índices más altos de bienestar. Si bien es relativo y particular el entendimiento de la felicidad, lo cierto es que hay países donde la gente indica pasarla mejor, tener bienestar, tranquilidad y estar interesado en vivir. Creemos que estos aspectos tienen mucho que ver con la felicidad y el sentido en la vida. Lo que hemos podido revisar sobre el tema indica que, además de ciertos estilos de personalidad en la gente, existen condiciones socioeconómicas y educativas que promueven un estilo de vida más óptimo, tales como un buen ingreso económico, acceso a educación y posibilidades de atención médica. Sin embargo, puede faltar el dinero, puede haber incomodidades y contratiempos pero si tenemos aún una meta, un objetivo, algo o alguien que sea valioso de alguna forma, si tenemos amor (aunque suene muy cursi hoy en día), si lo recibimos y lo podemos dar, o algo por qué luchar, el sentido resultante hace que mantengamos la fuerza. Por encima de las necesidades económicas o de logro está la necesidad de sentido dice el psicoterapeuta Viktor Frankl, y para eso nos recuerda en sus textos algunos reportes de personas con problemas económicos y laborales que no entraban en depresión (o en agresión y adicciones, la "triada neurótica de masas") ni llegaban al suicidio (Frankl, 2000).

Pensamos en cómo hoy día, aunque no es reciente - de esto ya hace algunas décadas-, los medios nos venden la idea que tener es ser, que comprando y acumulando objetos lograremos ser felices. Recordamos dos frases, una señalada como autoría de Sócrates cuando iba a los mercados y decía "cuántas cosas hay que no necesito" y otra de Erich Fromm, "si soy lo que tengo y lo que tengo lo pierdo, ¿entonces quién soy? (Fromm, 1999, p. 348), $y$ vemos qué distinto a lo que hoy vivimos: la pretensión postmoderna de la búsqueda del sentido y de la felicidad afuera de uno, no dentro. (Arboccó, 2014b). El profesor, sociólogo y filósofo Zygmunt Bauman indicaba lo siguiente:

la sociedad de consumidores implica un tipo de sociedad que promueve, alienta o refuerza la elección de un estilo y una estrategia de vida consumista, y que desaprueba toda opción cultural alternativa; una sociedad en la cual amoldarse a los preceptos de la cultura del consumo y ceñirse estrictamente a ellos es, a todos los efectos prácticos, la única elección unánimemente aprobada", seguidamente señala " $n i$ bien aprenden a leer, o quizá incluso desde antes, se pone en marcha la "adicción a las compras". No hay estrategias de entrenamiento diferenciadas para niños y niñas: el rol del consumidor, a diferencia del rol del productor, no tiene género específico. En una sociedad de consumidores todos tienen que ser, deben ser y necesitan ser "consumidores de vocación", vale decir, considerar y tratar al consumo como una vocación (Bauman, 2007, p.78-80).

Es necesario señalar que Erich Fromm, anteriormente citado, ya decía hace décadas como todo un visionario que el capitalismo moderno necesita hombres pasivos, que cooperen mansamente y en gran número, $y$ que a pesar de eso, se sienten libres. En su libro "La vida auténtica" él nos recuerda lo siguiente: 
la propaganda moderna, en un amplio sector, no se dirige a la razón sino a la emoción; como todas las formas de sugestión hipnótica, procura influir emocionalmente sobre los sujetos, para más tarde someterlos a su vez desde el punto de vista intelectual. Esta forma de propaganda influye sobre el cliente, y recurre a toda clase de medios: la incesante repetición de la misma fórmula; el influjo de la imagen de alguna persona de prestigio, como puede ser la de alguna dama de la aristocracia o la de un famoso boxeador que fuma tal marca de cigarrillos; por medio del sex-appeal de alguna muchacha bonita, atrayendo de ese modo la atención del cliente $y$ debilitando al propio tiempo su capacidad de crítica; mediante el terror señalando el peligro del " $\mathrm{mal}$ aliento" o de alguna enfermedad de nombre misterioso; o bien estimulando sus fantasías de un cambio imprevisto en el curso de su propia vida debido al uso de determinado tipo de camisa o de jabón (Fromm, 2007b, p.98-99).

\section{Sociedad esquizofrenógena}

Esquizofrenógena significa que produce esquizofrénicos(as). Puede ser una madre la que lo haga, puede ser una familia así como una sociedad en su conjunto, con sus contradicciones, doble moral y malos modelos. Gran cantidad de sociedades se mueven dentro de vínculos extraños y ambivalentes, con dobles (y hasta triples) mensajes y órdenes. Algunos ejemplos bastarán para aclarar esto. Nos dicen desde pequeños que está mal mentir y robar pero desde entonces vamos viendo en casa, en la escuela y luego a las propias autoridades del país (policías, jueces, alcaldes, presidentes) hacerlo; esto es mentir, robar, transgredir las propias normas por ellos señaladas.

Nos dicen también que un hombre vale por lo que lleva dentro y que hay que ser más que parecer; sin embargo, luego observamos en la
TV cómo la gente usa máscaras todo el tiempo $y$ viven orientados a "producirse" es decir, a fabricarse en una cosa que no son, convertirse en un producto que estará en la vitrina de la vida esperando ser mirado, aceptado y hasta adquirido.

Escuchamos esa cantaleta de que somos únicos e irrepetibles pero los padres se asustan cuando escribimos con la mano izquierda y nos hacen escribir con la diestra, o se asustan cuando somos más lentos o más cinéticos que los demás y en esos casos nos etiquetan, nos diagnostican y hasta nos medican, todo para que seamos "normales", lo cual significa, ser parecidos a los demás, al promedio, a la norma. De genuinos y particulares, nada.

Nos hablan de que el respeto y el amor al prójimo debe ser la línea rectora de nuestros vínculos y relaciones, pero desde chicos vemos cómo papá y mamá no se llevan, discuten y hasta se agreden, siendo agredidos nosotros de paso, directa e indirectamente, tanto verbal como físicamente. ¿Entonces?

Nos enseñan a respetar a las damas, a no jugar con ellas y a cuidar nuestras relaciones de pareja, pero al mismo tiempo muchos realitys nos muestran todos los días, chicas lindas en diminutas prendas mostrando más de la cuenta y siendo intercambiadas por los chicos lindos ( $y$ fortachones) en romances ( $a$ veces falsos y construidos en los mismos sets de TV) que duran lo que dura una temporada del programa. ¿Cómo que puede llegar a confundir en los niños y jóvenes el valor del compromiso y el respeto a nuestro cuerpo y al del otro, no?

No debemos consumir alcohol ni drogas pues eso está mal, pero siendo niños participamos en juergas familiares interminables en casa y nos enteramos luego de la costumbre de algunos de esos familiares de automedicarse hasta el hartazgo cuando las cosas se ponían difíciles, y es que algunas pastillas para los nervios no caen mal. Mientras tanto en las noticias nos enterábamos de la caída de otro pequeño vendedor de coca, que saldría unas semanas después de haber arreglado convenientemente con algunos abogados, policías y fiscales. Pero ni hablar de los grandes narcotraficantes, esos 
que cenan con altos mandos militares y beben whisky mientras hablan de la grandeza de algunos otros países desarrollados (Arboccó, 2016).

De la esquizofrenia, dice la RAE: "Grupo de enfermedades mentales correspondientes a la antigua demencia precoz, que se declaran hacia la pubertad y se caracterizan por una disociación específica de las funciones psíquicas, que conduce, en los casos graves, a una demencia incurable" (RAE, 2017). Saquen ustedes sus conclusiones.

\section{¿Todo es descartable?}

Hoy existe un reemplazo muy rápido en el ámbito de las relaciones amorosas, e incluso las relaciones profesionales están fragmentadas. Ya no se trata más de "el" empleo de toda la vida. Todo eso tiene que ver con la cultura del exceso, de la caducidad, que esclaviza las personas

Olgária Matos

Nunca antes el ser humano había producido tanta basura como en los últimos cincuenta años. Y esto ocurre porque desde el siglo pasado vivimos una época donde se producen muchas cosas, las cuales deben renovarse continuamente. Elmercadoestá hechoparaque el tiempo de caducidad de las cosas (muebles, aparatos de telefonía, computadoras, TV, prendas) sea corto. Así, por más que cuidemos nuestras pertenencias, vamos a tener que renovarlas al ser sus repuestos muy costosos o inexistentes. Inclusive la recomendación del técnico experto es "mejor compre otro equipo".

Y de esta manera, entramos en una sociedad de lo descartable. No solamente descartamos objetos sino también estamos acostumbrándonos a relacionarnos así ya no solo con las cosas sino con las personas, con las instituciones. Hay algunos lugares del planeta donde los matrimonios duran menos de seis meses. Parece que el compromiso no está siempre presente en nuestra vida.

En la cultura de la caducidad, estamos atrapados en una perenne renovación de las cosas y de las relaciones. Esto nos recuerda las reflexiones del periodista y escritor uruguayo Marciano Durán al respecto:

lo que pasa es que no consigo cambiar el equipo de música una vez por año, el celular cada tres meses o el monitor de la computadora todas las navidades. Es que vengo de un tiempo en el que las cosas se compraban para toda la vida. Es más, ise compraban para la vida de los que venían después! La gente heredaba relojes de pared, juegos de copas, vajillas y hasta palanganas. Hoy todo se tira, todo se desecha y, mientras tanto, producimos más y más y más basura. ¿¿Será que cuando las cosas se consiguen fácilmente, no se valoran y se vuelven desechables con la misma facilidad con la que se consiguieron? (Durán, 2006).

La sociedad contemporánea que nos toca vivir —capitalista, productora, consumista, mediática y tecnocrática- está definida por la presencia de lo descartable y a corto plazo. Hoy, nada dura, ni una refrigeradora, ni un romance, y eso es penoso, nos resta como seres humanos. Nos oponemos a eso pero así están las cosas y esto no es negativismo ni fatalismo, es realismo. Y esta es la sociedad que les estamos dando como modelo y en herencia a los más pequeños, les enseñamos a ser engreídos, compradores obsesivos, egocéntricos, poco empáticos, rápidamente frustrados y con muy poco compromiso por las cosas y las personas.

\section{La sociedad abandonada}

Lanzamos una pregunta: ¿Nuestra sociedad promueve una cultura saludable? La respuesta, después de pensarla con calma, es NO. No como quisiéramos, no como hace falta. Pasaremos a explicarla. 
Estas últimas cuatro décadas se han caracterizado en nuestro país por la presencia de un sistema que promueve el consumismo (con un plástico en el bolsillo puedo comprar todo lo que antes debía hacer con dinero en efectivo), la adoración al cuerpo en desmedro de la mente (Joaquín Sabina lo recuerda cuando nos dice "los gimnasios están llenos, las librerías siguen vacías"), la corrupción (es sintomático que nuestros últimos cuatro presidentes tengan problemas con la ley, y dos de ellos purguen prisión ${ }^{5}$ ); el miedo (la violencia reina y pareciera que las fuerzas del orden no ordenan nada) y la paranoia (se estima que nueve de cada diez peruanos no se siente seguro al salir de casa, nos incluimos); además, se promueve la incertidumbre (no sabemos si se cambiarán leyes o se modificarán las reglas de juego en el sector empresarial, académico y hasta deportivo). También se estimula el exceso $y$ un hedonismo primario descontrolado: licorerías, hostales, bares, prostíbulos. Reina el desorden (Caso Utopía, Caso Mesa Redonda, Caso Larco Mar, Caso Emporio Las Malvinas, Caso Cerro San Cristóbal), y, por último, para no hacer la lista más extensa aún, se promueve la valorización de lo efímero en vez de lo duradero, de ahí que se ha bautizado a estos tiempos como la "sociedad light" o la "sociedad del vacío".

Con este diagnóstico, surge la pregunta que César Vallejo le hace al Ministro de Salud en su poema "Los nueve monstruos": ¿Qué hacer? (Silva-Santisteban, 1997). La manera de afrontar esto y no descubrimos nada nuevo al decirlo, es desde un enfoque interdisciplinario.

Padres de familia, educadores, jueces, políticos, comunicadores, periodistas, psicólogos, trabajadores sociales, médicos, abogados, economistas, entre otros profesionales, deben con carácter de urgencia humanizar sus prácticas, contribuir a mejorar esta sociedad que huele a malograda hace rato. Recordamos haber leído un texto del Dr. Carlos Alberto Seguín, de hace más de cuarenta años donde indicaba que la nuestra era iuna sociedad enferma! (hace cuarenta años de esto).
Planificar y cuidar nuestras familias es tarea de todos, armonizar las escuelas y buscar que sean lugares donde no solo se "dejan" a los muchachos mientras los padres trabajan, sino convertirlos en segundos hogares donde podamos encontrar nuestros talentos, limar imperfecciones, convivir pacíficamente, aprender a amar la lectura, conocer nuestra historia y forjar ciudadanos con civismo. Humanizar las empresas y no solo ver al hombre como una pieza más de un engranaje que debe producir tantas utilidades al año, $y$, finalmente, pero muy importante en estos tiempos mediáticos, mejorar los medios como la TV, la radio y la prensa, que hoy día suelen vivir del escándalo, la tontería, lo banal y el chisme.

Otro pensador de estos tiempos, el filósofo y sociólogo francés Giles Lipovetsky en la misma línea nos invita a reflexionar si estos tiempos venideros no son oportunos para el desenfreno, el exceso pero también para la apatía, la indiferencia y el vacío. En su famosa obra "La era del vacío" señala al inicio a manera de presentación del ensayo:

El individualismo hedonista y
personalizado se ha vuelto legítimo
y ya no encuentra oposición;
dicho de otro modo, la era de la
revolución, del escándalo, de la
esperanza futurista, inseparable
del modernismo, ha concluido. La
sociedad posmoderna es aquella en
que reina la indiferencia de masa,
donde domina el sentimiento de
reiteración y estancamiento, en
que la autonomía privada no se
discute, donde lo nuevo se acoge
con lo antiguo, donde se banaliza
la innovación (Lipovetsky, 2000,
p. 9).

Y seguidamente afirma: "Ya ninguna ideología política es capaz de entusiasmar a las masas, la sociedad posmoderna no tiene ídolo ni tabú, ni tan sólo imagen gloriosa de sí misma, ningún proyecto histórico movilizador, estamos ya

\footnotetext{
5 Al momento de escribir este artículo, los Sres. Alberto Fujimori y Ollanta Humala se encuentran en prisiones peruanas.
} 
regidos por el vacío, un vacío que no comporta, sin embargo, ni tragedia ni apocalipsis" (ob. cit. p. 9-10).

Nuestra sociedad está enferma (Arboccó, 2017), reconozcámoslo, y tratemos de darle vida desde donde nos toque. Esto es deber de todos.

\section{No olvidar: El ser humano es una tarea}

\section{El YO no es algo que ES, es algo que SERÁ. Es una TAREA. \\ Søren Kierkegaard}

El filósofo danés nos invita a preguntarnos cuál es nuestro trabajo, nuestra obra o aporte en esta vida. Cuando muchas personas solo se muestran en su versión de consumidores perpetuos - cosa muy común en esta sociedad - la sentencia invita a pasar al lado de los productores, de los que construyen. Algunos solo consumen, otros, además, aportan, en ese sentido, se comprometen con su TAREA.

Es interesante que la palabra feliz venga del latín felix que significa fecundo. Cuentan que el escritor y naturalista Plinio decía que los árboles que no daban frutos se llamaban "infelices". Claro, hay varias acepciones para el término feliz así como muchas definiciones y teorías sobre la felicidad, pero pensamos que también es significativo asociar ambos conceptos: feliz y fecundo, feliz y fértil.

Algo fecundo es algo que produce, que crea, y Kierkegaard deja en claro que los seres humanos no somos algo definido, terminado, sino más bien algo que vamos siendo, algo que somos en un movimiento continuo mientras estamos vivos. Movimiento que nos da el ser organismos pensantes (cuando lo somos), con consciencia y libertad, como nos veía el existencialista danés. Otros pensadores, caen en la idea parecida que el hombre es un ser que construye, que crea, que trasciende su vida misma a través de su obra, de su trabajo, de lo que cada uno es capaz de hacer. Asimismo, al hablar de una tarea, pensamos en un tiempo y ese tiempo está fijado por nuestra finitud. No somos eternos y eso nos deja solo un margen finito, una temporalidad (nuestra vida misma) para concluir nuestra obra. Es inevitable así, la ansiedad existencial que acompaña a todo esto, pero no es una ansiedad patológica que requiera psicoterapias o psicofármacos; es el precio por ser libres y por tener que responsabilizarnos de esa libertad (responsabilidad).

En su libro El dilema del hombre, el psicólogo y psicoterapeuta existencial Rollo May nos dice lo siguiente "Cada ser humano sabe que morirá, aunque ignora cuándo; anticipa su muerte mediante la conciencia de sí mismo. Es probable que enfrentar esta ansiedad normal ante la finitud y la muerte constituya, de hecho, el incentivo más eficaz del individuo para extraer lo máximo posible de los meses o años que le faltan para que la muerte lo derribe" (May, 2000; p. 88). Pensamos que el hombre es un proyecto, a veces trunco, a veces realizado; $y$ es tarea de la familia, la escuela y el Estado en su conjunto, brindar posibilidades de desarrollo humano para que cada miembro de nuestra colectividad tenga opciones de alcanzar su tarea, de dejar obra hecha. Cuando esto no ocurre, no solo se pierde una posibilidad humana (algo que hubiera podido llegar a SER), al mismo tiempo se comete un delito, una inmoralidad.

El ser humano no está totalmente condicionado sino que al final de cuentas es el que toma las propias decisiones, el que encuentra valores, el que asume actitudes. Como dice Jean Paul Sartre, también somos lo que hacemos con lo que hicieron de nosotros. Aunque hay que ser claro al decir que es muy difícil conseguir bienestar en un lugar donde no hay orden, donde las posibilidades son escasas, donde no hay trabajo digno y la corrupción es un mal generalizado, por eso la labor de los gobiernos es cuidar que todos tengan la debida oportunidad de desarrollar sus posibilidades.

\section{Algunas conclusiones hasta aquí:}

- Vivimos dentro de lo que algunos denominan sociedades postmodernas, caracterizadas por un consumismo exagerado y el 
espacio digital; los medios masivos hoy se convierten en transmisores de la verdad además desaparecen las grandes figuras carismáticas y surgen infinidad de pequeños ídolos que duran hasta que surge algo más novedoso y atractivo (fomentado por los medios).

- El hombre basa su existencia en el relativismo y la pluralidad de opciones, al igual que el subjetivismo impregna la mirada de la realidad. Hay una pérdida de la fe en la razón y la ciencia, pero en contrapartida se rinde culto a la tecnología. Y una "psicología del éxito" mal entendida como desarrollo individual, consumismo, crecimiento económico, mayor cantidad de bienes materiales acumulados y la cultura de la imagen.

- Pensamos que toda esta cultura del bullicio, el hedonismo más básico $e$ instintivo y una nueva adicción por la tecnología y las redes sociales, comparte la época de un hombre alienado, estresado, aburrido, también asustado y con problemas fuertes de identidad y de vacío existencial.

- Muchos jóvenes viven sus vidas sin comprometerse, sin "sacarle el jugo", se les ve cansados, aburridos, desesperanzados, ausentes, apáticos; y los que tenemos unos años más y hemos sobrevivido a nuestra infancia, a nuestros padres, a la pubertad, al torbellino adolescente y al sistema en pleno y hemos podido encontrar propósitos, establecer objetivos y darle un sentido a nuestra existencia, de pronto podemos ayudar a movilizarlos y a que vean que la vida (a pesar de la cuota de dolor existencial inevitable que trae) nos brinda posibilidades y nosotros también podemos (y debemos) elegir y tomar decisiones y responsabilizarnos de lo que nos pasa.

- Un proyecto de vida sólido quizá formado desde pequeños podrá ayudarnos a convivir en esta época acelerada, tecnocrática, competitiva, consumista y de estímulos mediáticos insustanciales, las más de las veces, donde lo inculto y chabacano se posiciona gracias a los medios a la cultura y a la razón.

- Consideramos que es tarea de la familia, la escuela y el Estado en su conjunto, brindar posibilidades de desarrollo humano para que cada miembro de nuestra colectividad tenga opciones de alcanzar sus posibilidades. No olvidemos que el ser humano es un proyecto, una posibilidad; a veces trunca, otras concluida. 


\section{REFERENCIAS}

Arboccó de los Heros, M. y O’Brien, J. (2012) Impacto de la televisión basura en la mente y la conducta de niños y adolescentes, en Avances en Psicología 20 (2), pp.43 - 57. UNIFÉ, Lima.

Arboccó de los Heros, M. (2014) Consume peruano, consume, en Diario Oficial El Peruano, p. 12, 24 de julio del 2014.

Arboccó de los Heros, M. (2015) Psicología, psicoterapia y sociedad. Reflexiones Humanístico Existenciales. Avances en Psicología, 1. 49-60. Lima: Universidad Femenina del Sagrado Corazón.

Arboccó de los Heros, M. (2016) Sociedad esquizofrenógena, en Diario Oficial El Peruano, p. 12, 9 de abril del 2016.

Arboccó de los Heros, M. (2017) La Sociedad abandonada, en Diario Oficial El Peruano, p. 12, 18 de enero del 2017.

Bauman, Z. (2007) Vida de consumo. Buenos Aires: Fondo de Cultura Económica.

Denegri, M.A. (2014) Poliantea. Fondo Editorial de la Universidad Inca Garcilaso de la Vega: Lima.

Durán, M. (2006) Desechando lo desechable. Recuperado de http://www.marcianoduran.com. $u y / ? p=176$, el 5 de enero del 2015.

Frankl, V.E. (2000) El hombre doliente. Barcelona: Editorial Herder.

Frankl, V.E. (2004) El hombre en busca de sentido. Octava impresión. Barcelona: Herder.

Fromm, E. (1964) Psicoanálisis de la Sociedad Contemporánea. Hacia una sociedad sana. Sexta. Edición. Fondo de Cultura Económica: México

Fromm, E. (1999) Tener o ser. Madrid: Fondo de Cultura Económica.

Fromm, E. (2007a) El arte de amar. Barcelona: Editorial Paidós.

Fromm, E. (2007b) La vida auténtica. Barcelona: Editorial Paidós.

García, C. (2010) La vida es una moneda. El arte de vivir. Barcelona: Plataforma Editorial.

Gergen, K.J. (2002) The challenge of absent presence, In Katz, J. Aakhus, M.(Eds.), en Perpetual Contact: Mobile Communication, Private Talk, Public Performance, Cambridge: Cambridge University Press pp. 227-241.

Gómez, R. (2013) Relación psicoterapéutica. Enfoque fenomenológico existencial. Fondo Editorial de la Universidad Inca Garcilaso de la Vega: Lima.

La Rosa, A. (2012) Teléfonos móviles, comunicación e interacción, en Avances en Psicología, 19 (1), pp. 69-79. UNIFÉ, Lima.

Lipovestky, G. (2000) La era del vacío. Ensayos sobre el individualismo contemporáneo. 
Décimo tercera edición. Barcelona: Editorial Anagrama.

Matos, O. (Set. 2014) Náufragos de la modernidad. En entrevista con Ana Paula Orlandi, Traducción: Katerina Valdivia Bruch. Copyright: Goethe-Institut Brasilien. Recuperado de: http: // www.goethe.de/ins/co/es/bog/kul/mag/fok/zei/13268288.html, el 20 de diciembre del 2014.

May, R. (2000) El dilema del hombre. Respuestas a los problemas del amor y de la angustia. España: Gedisa Editorial.

RAE, Diccionario de la Real Academia Española (2017) Diccionario de la Lengua Española. Vigésima Tercera Edición. Edición del Tricentenario. Versión virtual.

Sartori, G. (2004) Homo videns: la sociedad teledirigida. España: Edit. Taurus.

Savater, F. (2007) Las preguntas de la vida. Barcelona: Editorial Ariel.

Silva-Santisteban, R. (1997) Poesía completa de César Vallejo. Lima: Fondo Editorial de la Pontificia Universidad Católica del Perú.

Fecha de recepción: 31-01-17

Fecha de aceptación: 07-09-17 